\title{
ESPEQAL UDERANÇA
}

\section{Trajetórias de vida e liderança}

A influência que as experiências de vida exerce sobre líderes é uma questão intrigante. Na verdade, os líderes de hoje são pessoas cujas vivências passadas foram fundamentais para que se tornassem empreendedores ou executivos. Este artigo é resultado de uma pesquisa com presidentes executivos e presidentes empreendedores que buscou entender as origens da liderança e as formas de transmiti-la.

por Betaria Tanure FDC - INSEAD e Roberto Gonralez Duarte PUC/MG

0 tema liderança tem sido amplamente explorado e discutido nos últimos anos, seja na academia, seja na mídia mais voltada para os executivos. M esmo assim, ainda gera muitas controvérsias: o que faz algumas pessoas se destacarem como líderes e outras não? Q uais as características principais dos líderes? Eles nascem líderes ou se formam ao longo da vida? As teorias sobre liderança formuladas nos Estados Unidos são válidas para o Brasil ou para o Japão? E as formuladas aqui ou no Japão, são válidas nos EUA?

Realizamos uma pesquisa sobre o tema, parte dela em parceira com a
Wharton University of Pennsylvania. Do braço brasileiro participaram 36 presidentes, além de 324 executivos, de empresas familiares e não-familiares, nacionais e estrangeiras, de médio e grande porte. Nossa análise leva em conta dois grupos de líderes: os "empreendedores" e os "executivos". 
Chamamos de empreendedores os presidentes que criaram seus próprios negócios e de executivos, os que modelaram suas carreiras na gestão das organizações e hoje dirigem empresas não criadas por eles (o que não significa que, lato sensu, não sejam empreendedores).

Discutimos aqui os aspectos que diferenciam ambos os grupos e os que são comuns, analisando de que forma eles foram fundamentais para que os indivíduos pesquisados se tornassem líderes. Focalizamos a trajetória dessas pessoas, em particular as experiências ou situações passadas consideradas relevantes, as dificuldades de percurso pessoais e/ou profissionais e as influências consideradas mais decisivas. São abordados ainda os pontos fortes e fracos desses líderes e, à luz dessas discussões, abordamos, por último, a formação de futuros líderes.

Trajetória de executi vos. Ao se analisar a história pessoal dos indivíduos que participaram de nossa pesquisa, observa-se quea dos presidentes executivos é mais linear, caracterizando-se por maior sofisticação acadêmica e profissional. Todos possuem curso superior - especialmente nas áreas de engenharia e administração - , e a maioria graduou-se em universidades públicas. Uma parte deles fez pós-graduação no exterior.

Embora al guns tenham trabalhado desde cedo a fim de financiar seus estudos, a maioria é originária de famílias de classe média, excetuando-se uns poucos herdeiros. De maneira ge ral, fica bastante evidente nesse grupo a importância dos estudos como meio

0 líder, na verdade, não é o super-homem ou a mulhermaravilha que muitos imaginam ou querem demonstrar ser. Esse é um mito criado para atender as expectativas da sociedade, que são especialmente fortes nos países onde a cultura enaltece 0 fazer, a agressividade, a ousadia e as relações de poder.

de possibilitar a mobilidade social e profissional. Esse valor é forjado no seio da família, com ênfase ainda maior naquelas menos favorecidas do ponto de vista socioeconômico, nas quais a educação é considerada fundamental para essa ascensão.

Do ponto de vista da atuação profissional, nota-se a mesma estabilidade; isto é, com raras exceções, a maioria dos presidentes executivos construiu a carreira em uma única empresa. Alguns tiveram a oportunidade de passar por mais de uma organização ou de atuar no exterior, mas, independentemente dessas outras experiências, a maior parte trabalhou muitos anos na mesma empresa antes deatingir a presidência. Normalmente, começaram em posições mais simples da hierarquia e, de maneira gradual, ocuparam posições em diferentes áreas antes de serem, finalmente, nomeados presidentes. São raras, então, as situações de executivos que foram contratados diretamente para a posição.

Trajetórias de empreendedores. Já entre os presidentes empreendedores, essa estabilidade não é uma característica freqüente.
A história pessoal e a profissional são claramente marcadas por altos e baixos. A inquietação, aspecto comum entre eles, talvez os leve a "fugir" da estabilidade. De toda forma, em comparação com o grupo de presidentes executivos, os empreendedores têm a "carreira" mais marcada por sucessivas mudanças radicais. N esse grupo, é bem menor a proporção dos que cursaram a universidade.

Os empreendedores também tiveram uma história marcada por muitas dificuldades. Por necessidade financeira, grande parte deles começou a trabalhar muito cedo e exerceu diferentes atividades antes de fundar sua empresa. 0 trabalho - ou, mais precisamente, a vontade de empreender um negócio efazer al go diferenteparece ter dominado essas pessoas desde cedo. Fundamentalmente, a história de vida dos indivíduos desse grupo é caracterizada pela constante inquietude e pela persistência na concretização de um sonho.

Mas não são apenas os problemas financeiros que distinguem a trajetória desses presidentes. Alguns identificam grandes perdas afetivas como marcas que modelaram sua personalidade e, por conseqüência, influenciaram 
sua história profissional. Outros re latam o nível de exigência e desafio imposto pelos pais desde a infância como determinantes para que não se curvassem aos desafios que um líder enfrenta. 0 fato, por exemplo, de, aos 10 anos de idade, um menino ser obrigado pelo pai a realizar algumas duras tarefas para se tornar "merecedor" da tão desejada bicicleta trará em outros momentos de sua vida uma atitude diferente diante de objetivose conquistas. E talvez uma força maior diante de grandes obstáculos.

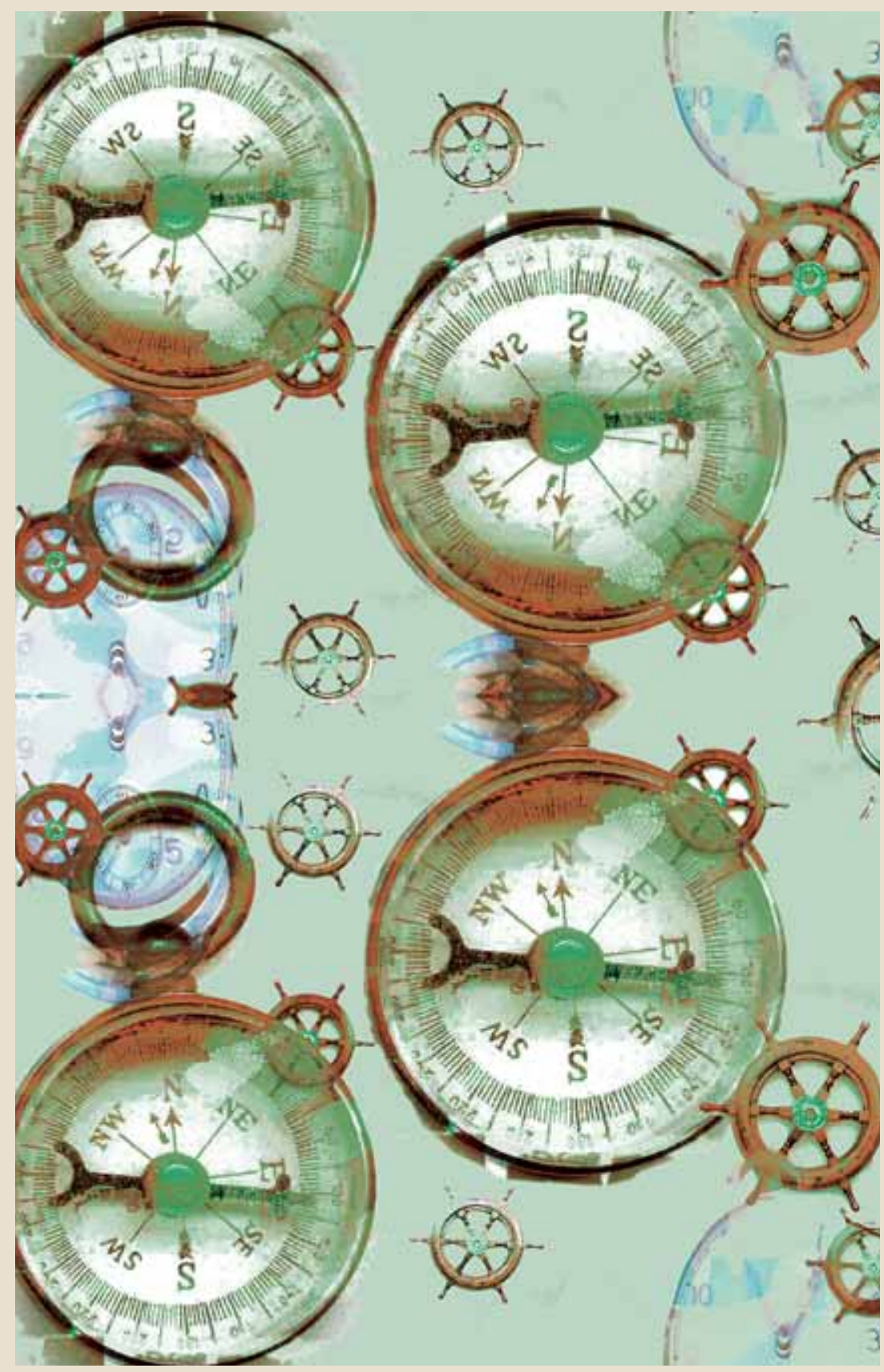

Executivos versus empreendedores. Umasignificativa diferença entre os dois grupos é o valor simbólico da posição de presidência. Para o executivo, a chegada ao topo, muitas vezes, levou al gum tempo. Os degraus foram sendo gal gad os gradativamente. O cargo sinaliza uma história executiva de sucesso em organizações que têm processos e sistemas estruturados. Raramente o executivo que está em uma empresa como essa, especialmente se ela for multinacional, necessita buscar informações sobre o que acontece no mundo dos negócios. As informações fluem naturalmente no cotidiano. 0 conjunto de atribuições do presidente é bastante definido. 0 entourage cuida de toda a infra-estrutura necessária.

Para o empreendedor, os limites desse conjunto de funções são mais difusos: a presidência pressupõe um espectro mais amplo de papéis, que vai, por exemplo, do encontro com autoridades governamentais até a participação direta no processo produtivo. A própria história - de começar uma empresa do zero - reforça esse modelo, eo empreendedor, além de gostar do amplo espectro, dele se orgulha. Além disso, diferentemente do que ocorre com o presidente executivo, a função "presidente" vem sendo exercida por ele desde o primeiro momento da empresa.

Um outro ponto comum aos dois grupos diz respeito às influências consideradas decisivas na vida das pessoas e, em particular, no exercício da liderança. A importância desse aspecto está, às vezes, estreitamente atrelada a problemas vivenciados. Ou seja, nos momentos 
mais difíceis da vida pessoal e/ou profissional do indivíduo, houve alguém que foi marcante, que o encorajou e estimulou a superar as dificuldades.

Quase sempre essa influência veio de al gum ente familiar próximo, normalmente pai ou mãe. Um presidente relata que, ainda muito jovem, solicitou à mãe que o ajudasse a redigir uma carta para uma vaga em uma empresa. A situação era nova para ele, que se sentia um tanto amedrontado. Ela se recusou a "ajudá-lo". Depois de ouvir um claro e motivador "Você dá conta", ele se sentiu forte e "obrigado" a vencer o desafio de redigir a carta sozinho. Para al guns, essa influênciaé representada pelo fato de ter tido um modelo forte de liderança ainda nos primeiros anos de vida.

A influência decisiva pode vir ainda de um profissional com quem 0 líder trabalhou ou conviveu, geralmente o presidente que lhe antecedeu ou, no início da carreira, um chefe. Para alguns isso significou conhecer valores que acabaram constituindo uma base sólida de seu caminho profissional. N ossa pesquisa revel ou al gumas experiências importantes nesse sentido.

A marca da experiência. A despeito das diferenças de trajetória desses presidentes, a maioria, de ambos os grupos, como já dito, vivenciou em al gum momento de sua vida situações intensas, às vezes difíceis. Tais obstáculos são vistos com orgul ho e muitos creditam a eles um papel fundamental em suas vidas.

Segundo Kets de Vries, professor e diretor do centro de liderança do

Não resta dúvida de que o desafio do verdadeiro líder é transferir responsabilidades aos membros de seu grupo para estimular a autoconfiança e a auto-estima, criando um contexto marcado pela justiça no qual as pessoas se sentem estimuladas e, portanto, geram resultados empresariais sustentáveis.

Insead, muitos líderes se tornaram o que são por razões negativas. Eles sentem uma forte necessidade de reverter as situações difíceis que enfrentaram nos períodos iniciais de suas vidas. De fato, as dificuldades são importantes porque têm um poder transformador. A frase de um presidente reforça essa idéia: "Só crescemos pelo sofrimento".

Além disso, certas experiências negativas tornam-se meios de desenvolver habilidades essenciais para a liderança efetiva. $N$ as palavras de um presidente executivo, "o momento difícil é que traz à tona a liderança e que faz o homem ser um líder". Assim, um líder se diferencia dos demais ao deixar de ser apenas um produto do passado, que sofre a ação, para interagir com seu ambiente futuro e construí-lo.

O líder seria, então, o indivíduo capaz de aprender com as circunstâncias mais desafiadoras, desenvolvendo a habilidade de agir corretamente em momentos demedo etambém sob efeito dele. Nessesmomentos, esselíder pode provocar sofrimento nas pessoas, ao desafiá-las, ao tomar uma medida impopular. Mas elenão hesita. Implementa as medidas necessárias. N o entanto, essa mesma pessoa, para ser caracterizada como líder, tem de saber fomentar boas relações: apóia, desenvolvee, por meio da confiança e da justiça, gera um ambiente adequado.

Ao observar a trajetória pessoal e profissional dos presidentes, as dificuldades que eles viveram e as influências mais importantes de suas vidas, podemos compreender, pelo menos em parte, por que se tornaram líderes. Ademais, a história dessas pessoas foi fundamental para forjar suas características principais do ponto de vista da liderança.

o líder, na verdade, não é o super-homem ou a mulher-maravilha que muitos imaginam ou querem demonstrar ser. Esseéum mito criado para atender as expectativas da sociedade, que são especialmente fortes nos países onde a cultura enaltece 0 fazer, a agressividade, a ousadia e as relações de poder. Tais características são típicas do Brasil e dos Estados Unidos, mas não existem da mesma forma, por exemplo, na Dinamarca ou na Holanda.

Pontos fortes e fracos. Quando temos a consciência de que um líder não é um ser com superpoderes, 
podemos ver que, se ele tem pontos fortes, também apresenta fraquezas. Em nossa pesquisa, observamos que tanto entre empreendedores como entre executivos a análise dos pontos fortes e fracos não pode ser desvinculada do estilo de liderança típico de cada país.

No Brasil, é ainda comum defrontar-se com líderes paternalistas e líderes autoritários. I soladamente, cada tipo é ineficaz. Em um ou em outro, não raramente o equilíbrio de estilos se dá de forma inadequada. 0 paternalista pode criar entre seus subordinados uma mentalidade de que tudo é permitido. Ele repreende, mas no minuto seguinte adula o repreendido. Dessa forma, o desafio imposto, ou o sofrimento gerado pelo feedback, perde o efeito. Entretanto, apesar desse sobe-e-desce emocional, o paternalismo pode gerar mais lealdade do indivíduo para com a organização, tendo em vista a relação emocional com o líder, quase um pai.

0 autoritário gera ou tros comportamentos: inibe as iniciativas, uma vez que tem todas as respostas corretas; abafa o empreendedorismo; estimula o fenômeno da "delegação para cima" e normalmente se cerca de pessoas que não têm coragem de dizer verdades tão necessárias. 0 lado positivo desse líder é sua capacidade de decidir mais rapidamente e, em países como o Brasil, comumente é carismático, o que seduz seus subordinados.

Porém, mesmo que esses estilos ainda sejam bastante comuns, não resta dúvida de que o desafio do verdadeiro líder é transferir res- ponsabilidades aos membros de seu grupo para estimular a autoconfiança e a auto-estima, criando um contexto marcado pela justiça no qual as pessoas se sentem estimuladas e, portanto, geram resultados empresariais sustentáveis.

Formando futuros líderes. Tomando como referência a trajetória das pessoas por nós investigadas, pode-se perguntar quais são os desafios que a preparação de futuros líderes impõe a elas. Se bem-sucedidos, os atuais líderes podem oferecer à sua família condições de vida materiais bem melhores do que as que tiveram no passado. Isso significa que os filhos não são submetidos a experiências adversas que foram consideradas decisivas para a formação de seus pais. Será que isso tem implicações, positivas ou negativas, para o desenvolvimento das novas lideranças?

No que diz respeito à figura materna, pilar crítico do desenvolvimento dos líderes, vale observar que muitas mães, hoje, em virtude de suas atividades profissionais e do envolvimento com suas carreiras, têm outra estrutura de relacionamento com os filhos que não é contrabalançada por mudanças significativas nas relações dos filhos com os pais. Esse não seria outro elemento importante na análise do desenvolvimento de novos líderes?

Poder-se-ia, então, afirmar que, nessa nova configuração familiar, na qual há ausência de grandes dificuldades financeiras e a presença tanto do pai quanto da mãe não é modelar, filhos de líderes estão condenados a não se tornarem líderes? A resposta é não. 0 fato de o filho nascer em "berço de ouro" não significa que não enfrentará outros obstáculos.

Líderes bem-sucedidos podem contribuir para a formação de filhos líderes ao estabelecer desafios e dificuldades que não são, necessariamente, financeiras. Da mesma forma, os pais, e mais fortemente as mães que desenvolveram uma carreira profissional que fez com que fossem taxadas de ausentes, podem também exercer uma influência importante na vida de seus filhos ao apoiá-los, ajudá-los na construção de sua auto-estima e na preparação deles para lidar com futuras frustrações e realizações ou mesmo servir de modelo de profissional bem-sucedido.

Ao optar pela carreira de executivo, seu filho terá oportunidades diferenciadas, a exemplo daquelas relacionadas à formação. 0 desafio está em superar a insuficiência de tempo de convivência para consolidar valores, em oferecer as condições emocionais para que o filho seja desafiado a buscar, constantemente, o caminho do crescimento.

Betania Tanure

Doutora em Administração

Profa. da Fundação Dom Cabral e Profa. convidada do Insead

E-mail: betaniat@fdc.org.br

Roberto Gonzalez Duarte Doutor em Administração

Prof. do Mestrado em Administração da PUC/MG

E-mail: robertoduarte@pucminas.br 